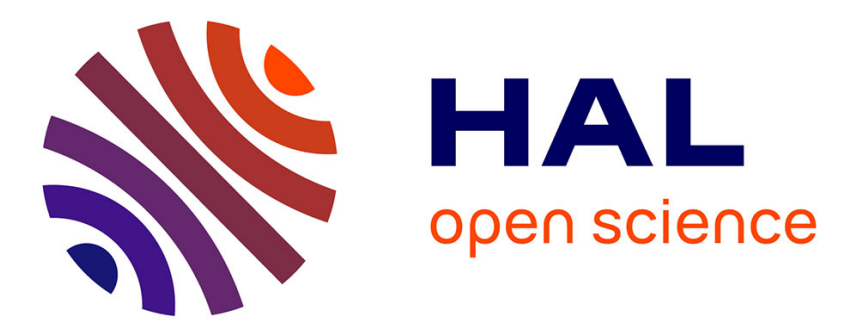

\title{
Preliminary study of a new CBR-Based application for voxelised Phantom creation: REEPH.
}

Maurice Bopp, Julien Henriet, Brigitte Chebel-Morello, Libor Makovicka, David Broggio

\section{- To cite this version:}

Maurice Bopp, Julien Henriet, Brigitte Chebel-Morello, Libor Makovicka, David Broggio. Preliminary study of a new CBR-Based application for voxelised Phantom creation : REEPH.. Singaporean-French IPAL Symposium. SinFra'09 IPAL : Image Perception, Access \& Language Lab, Feb 2008, Fusionopolis \& IMS, Singapore, Singapore. pp.107-115. hal-00377641

\section{HAL Id: hal-00377641 https://hal.science/hal-00377641}

Submitted on 22 Apr 2009

HAL is a multi-disciplinary open access archive for the deposit and dissemination of scientific research documents, whether they are published or not. The documents may come from teaching and research institutions in France or abroad, or from public or private research centers.
L'archive ouverte pluridisciplinaire HAL, est destinée au dépôt et à la diffusion de documents scientifiques de niveau recherche, publiés ou non, émanant des établissements d'enseignement et de recherche français ou étrangers, des laboratoires publics ou privés. 


\title{
PRELIMINARY STUDY OF A NEW CBR-BASED APPLICATION FOR VOXELISED PHANTOM CREATION: REEPH
}

\author{
MAURICE BOPP ${ }^{(1)}$, JULIEN HENRIET ${ }^{(1)}$, BRIGITTE CHEBEL-MORELLO ${ }^{(2)}$, \\ LIBOR MAKOVICKA $^{(1)}$, DAVID BROGGIO ${ }^{(3)}$ \\ (1) Institut FEMTO-ST, dept CREST 4 Place Tharradin, 25200 Montbéliard, France. \\ (2) Institut FEMTO-ST, dept AS2M 24rue Alain Savary, 25000 BesançonFrance. \\ (3) DRPH/SDI/LEDI, IRSN, BP-17 F, 92269 Fontenay-aux-Roses, France
}

\begin{abstract}
In the domain of radiation protection it is not always possible to perform an additional examination such as scanners or Magnetic Resonance Imaging (MRI) for a patient who has been accidentally radiated. However a medical diagnostic must be made as soon as possible to calculate the dosimetric balance. Currently this incidental calculation is based on the available voxelised phantoms which are $3 \mathrm{D}$ numerical reconstructions of the human body with the internal organs. The Case-Based Reasoning (CBR) is seen on the one hand like a problem solving method and on the other hand like a technology for the conception of intelligent systems. The ReEPh project (Research of Equivalent Phantom) strikes a new path in the field of problem solving methods in the radiation protection and uses the approach of the CBR to retrieve the set of the phantoms the most adapted to the irradiated victim. For this first version of ReEPh, the retrieval phase uses a Knn Algorithm (K nearest neighbours). We propose a measure of similarity and a confidence index to take into account the uncertainty implied by the possible missing characteristics of the victim. We have developed a graphic interface to view the cases retrieval, and to visually illustrate the combination of measures of similarity and confidence index.
\end{abstract}

\section{Introduction}

In the domain of radiation protection it is not always possible to perform an additional examination such as scanners or Magnetic Resonance Imaging (MRI) for a patient who has been accidentally radiated. The required technology may not be directly available or it would be advisable to avoid a radiation overexposure for a complementary examination in the case of a radiation accident. However a medical diagnostic must be made as soon as possible to calculate the dosimetric balance. Currently this incidental calculation is based on the available voxelised phantoms which may be far from the biometrical data of the victim. A voxelised phantom is a $3 \mathrm{D}$ numerical reconstruction of the human bodies with the internal organs. If it was possible to determine the phantom which resembles the most to the biometrical data of the victim and to adapt it to 
the victim characteristics, it would be much easier to calculate the precise dosimetric balance.

The Case-Based Reasoning (CBR) is seen on the one hand like a problem solving method and on the other hand like a technology for the conception of intelligent systems. There are several approaches for the development of intelligent systems and they have all the same intention: to analyze, understand or reconstruct the intelligence of the human brain. But the main ambition is not only the reconstruction of the human thinking; it is first and foremost the opening of new possibilities of problem solving methods. That is the reason why several disciplines like the Artificial Neural Network (ANN) or the CBR received a substantial boost in recent years. Nowadays we live in a time where it is more and more important to find quickly the required information in an enormous amount of knowledge. This is one of the main intentions of the CBR besides the intelligent further development of knowledge that already exists.

The ReEPh project (Research of Equivalent Phantom) strikes a new path in the field of problem solving methods in the radiation protection and uses the approach of the CBR to realise the aspects mentioned above. The idea is now to use the CBR-approach to create an application which permits to find the most similar phantom in a case-base and with the help of different rules to adapt this phantom to the characteristics of the irradiated victim.

The second part of this paper is a survey of the voxelised phantoms. After having described the principles of CBR in the third part, this paper presents the application we have implemented called ReEPh.

\section{A survey of voxelised phantoms}

A lot of work has been done around phantom design. I. Clairand [1] distinguishes mathematical phantoms from voxelised ones.

Mathematical phantoms use simple geometric figures to describe the organs. Used figures are spheres, cones or ellipses. In this category, most of nowadays mathematical phantoms are based on the W. S. Snyder's phantom [2]. The Oak Ridge National Laboratory (ORNL) Phantoms are evolutions of the K. F. Eckermann's one [3]. Male and female adult phantoms (Adam and Eva) of the GSF (Forschunszentrum fur Umwelt und Gesundheit) have been elaborated from MIRD [4]. I. Clairand also defined three male and three female phantoms with different dimensions. Whereas all these phantom models are Caucasian human being, G. I. Tanaka et al. elaborated an Asian one for Hiroshima survivors [5].

Due to the advances in computer technology, it is now possible to create more complex figures representing realistic 3D organs: voxelised phantoms. 
Most of them are elaborated using Magnetic Resonance Images and tomodensimetric data. The GSF digitized one man and one woman with medium build [6] and two children: an eight weeks old one called BABY, and a seven years old one called CHILD [7]. Nowadays, the most famous phantoms are NORMAN (for NORmal MAN) of the National Radiological Protection Board [8], and I. G. Zubal et al's phantom [9]. ADELAIDE [10] and GOLEM [11], elaborated by M. Zanki and A. Wittmann are also voxelised phantoms.

The purpose of many projects is to create anthromorphic phantoms as realistic as possible regarding one person in particular. G. Lorin de la Grandmaison et al. studied the organ weights of 684 Caucasian adults [12]. They have taken into account the patient's age, gender, weight, limb dimensions and body mass index. The objective of "the visible man" project is to create a $3 \mathrm{D}$ voxelised phantom using one's scanner [13]. Data are turned into voxels before the dosimetric computations [14]. A similar project called "the virtual man" has been performed by the ORNL [15].

In most of the case, well-known phantoms are stretched by some computer to correspond to one patient in particular. Software like MABDOSE and MIRDOSE which allow performing dosimetric reports are based on mathematical models [1]. Nevertheless, medical diagnoses require precision and speediness. We assume precision may be increased with phantoms which correspond to the victim. For all these reasons, we explored the possibility to use a tool of the Artificial Intelligence: the Case-Based Reasoning which principles are presented in the next part of this paper.

\section{CBR application for the radiation protection}

The intention of this preliminary work is the creation of fundament for the future work. Our main objective is to create an application for the radiation protection. To help clarifying this work in the first instance only the phantom of the thorax has been taken into account from the remaining phantom. We have chosen the case based reasoning to develop this application.

\subsection{The principles of the CBR}

Case Based Reasoning (CBR) is an approach to problem solving and learning, by reusing the solutions to similar problems stored as cases in a case base CBR. A case is an experience and an explanation during the episode of problem decision. Representation of cases is very diverse according to the nature of the task: diagnosis, planning, decision-making help, conception and so on [16]. However, case is composed of a description of the "problem" and a solution to solve it [17]. 
A case is placed in a Case Base and is called source case with which one will find out how to solve a new case. This new case is called "target case". A Case Base is a collection of decision-making cases. A new problem is solved by first, developing a target case who consists in characterizing the target case, by possibly supplementing the description of the new problem, then by retrieving one or more cases from the case base, reusing the case and revising the solution if need be, and retaining the new experience by adding it in the case base.

In our radiation protection application, each case is characterized by a thorax phantom and its descriptors. This application is able to memorise a case as a solved case in the case base, to create a new case, to extract information from a DICOM-File (Digital Imaging Communication in Medicine) which is the international standard format for medical image storage and exchange, and to compare two cases graphically.

In this preliminary study, we did not study the adaptation phase. This part requires further research work about the deformation rules to extrapolate a phantom from another. For example, how to turn a phantom into another one with the same characteristics but ten years older?

\subsection{The representation phase}

Each case is characterized by a thorax phantom and its descriptors. In this work we replace "target case" by "victim case" and "source case" by "model case" so that the terms are clear for the experts of radiation protection. In a model case the solution is the reference to the $3 \mathrm{D}$ phantom.

Each case is denoted by the pair $(D, \operatorname{Sol}(D))$. $D$ represents the problem part descriptors. It's a set of $n$ descriptors. $\left(d_{1}^{j}, \ldots, d_{n}^{j}\right)$ of the model case and $\operatorname{Sol}(D)$ is the solution of the problem: the reference to the $3 \mathrm{D}$ phantom of the thorax.

The victim case must be solved by the reasoning stage of CBR and is represented by the problem $\left(d_{1}^{i}, \ldots, d_{n}^{i}\right)$.

The list of required descriptors to characterize and establish the solution (the reference to the phantom of the thorax as mentioned above) follows the AFNOR clothing norm which has just been updated. The practice will also help us to study the pertinence of each descriptor.

In this list, we have identified some general characteristics, like the age, size, weight, gender and ethnical origin of the person. Other ones are very specific to the thorax organs (cardiac, lung and thorax volumes, thorax perimeter, and smoker/non smoker) and to the thickness of the tissues and the bones (proportion grease-muscle, wrist diameter, thickness of the rip bones, and acromiothoracic size) (cf. table1). 


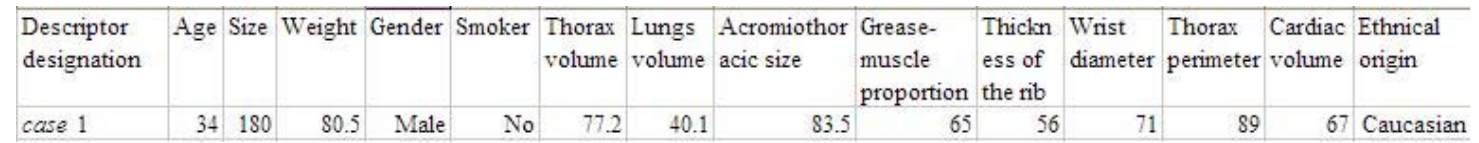

Table 1. The problem part descriptors of model case

Another point is that most of these values can be extracted by ReEPh directly from a DICOM-file which is the international standard format used to store and exchange medical images. The descriptors can take numerical, boolean or qualitative values.

\subsection{The elaboration of a case}

At this time, the elaboration phase consists in asking all known values of the descriptors as a questionnaire in a form. Some descriptors (like the thickness of the rip bones, the acromiothoracic size, the proportion grease-muscle and the volumes of the lungs, the thorax and the heart) may require further examination like scanning the victim, which often implies another radiation exposure. Even if this exposure radiation intensity may be insignificant regarding the accident irradiation intensity, it is better to avoid it if possible. In a future work, we will explore the possibility to extrapolate those values using only some of the other values. Most of those values appear in the standard medical image files DICOM. A ReEPh module can load such files and extract some of the metadata.

\subsection{The retrieval phase}

In this part, we present the way the similarity between two cases and the confidence index are calculated by $\mathrm{ReEPh}$. The main purpose of $\mathrm{ReEPh}$ is to retrieve the most similar phantom(s) of one victim whatever the number of known descriptors is. As a matter of fact, sometimes, it may be impossible to measure some volumes or to give the real value of many descriptors, but even in that case, the system has the obligation to render a solution..

To take into account the incompleteness, we propose a confidence index value depending on the missing values, and a similarity measure depending on the non-missing values. This similarity is calculated by ' $\mathrm{k}$ nearest neighbours' algorithm to retrieval similar cases.

We also introduced a parameter $\delta_{k}^{i}$ which indicates either the descriptor $k$ value for the victim case is missing or not.

\section{$\delta_{k}^{i}=\left\{\begin{array}{l}0 \text { if the descriptor value is missing } \\ 1 \text { if the descriptor value exists }\end{array}\right.$}

On the one hand, we know some descriptors are much more important than others. Consequently, each descriptor $k$ has a weight $\lambda_{k}$. 
The local similarity is first calculated for each numerical descriptor according the formula (1) and converted in values between 0 and 1 .

$$
\varphi_{i, j}^{k}=\frac{\Delta k-\left|d_{k}^{i}-d_{k}^{j}\right|}{\Delta k}
$$

For the qualitative or boolean descriptors like respectively ethnical origin or smoker/non smoker the value of formula (1) becomes

$$
\left\{\begin{array}{l}
\varphi_{i, j}^{k}=1 \Leftrightarrow d_{i}^{k}=d_{j}^{k} \\
\varphi_{i, j}^{k}=0 \Leftrightarrow d_{i}^{k} \neq d_{j}^{k}
\end{array}\right.
$$

Consequently, we obtained the formula (2) for the measurement of the similarity between the cases $i$ and $j$.

$$
S_{i, j}=\frac{\sum_{k=1}^{n} \delta_{k}^{i} \cdot \lambda_{k} \cdot \varphi_{i, j}^{k}}{\sum_{k=1}^{n} \lambda_{k} \cdot \delta_{k}^{i}}
$$

The similarity value is always between 0 and 1 . The more the cases $i$ (the victim case) and $j$ (the model case) are similar according the known values, the more this value is close to 1 .

Then, in each case we associate a confidence index decreasing with the number of unknown descriptors. So the confidence index takes into account the number of known values according the formula (3).

$$
I_{i}=\frac{\sum_{k=1}^{n} \delta_{k}^{i} \cdot \lambda_{k}}{\sum_{k=1}^{n} \lambda_{k}}
$$

Thus, the more values we know, the higher the confidence index is.

\begin{tabular}{|c|c|c|c|c|c|c|c|c|c|c|c|c|c|c|}
\hline $\begin{array}{l}\text { Descriptor } \\
\text { designation }\end{array}$ & Age & Size & Weight & Gender & Smoker & $\begin{array}{l}\text { Thorax } \\
\text { volume }\end{array}$ & $\begin{array}{l}\text { Lungs } \\
\text { volume }\end{array}$ & $\begin{array}{l}\text { Acromiot } \\
\text { horacic } \\
\text { size }\end{array}$ & $\begin{array}{l}\text { Grease- } \\
\text { muscle } \\
\text { proportion }\end{array}$ & $\begin{array}{l}\text { Thickness of } \\
\text { the rib bones }\end{array}$ & $\begin{array}{l}\text { Wrist } \\
\text { diameter }\end{array}$ & $\begin{array}{l}\text { Thorax } \\
\text { perimeter }\end{array}$ & $\begin{array}{l}\text { Cardiac } \\
\text { volume }\end{array}$ & $\begin{array}{l}\text { Ethnical } \\
\text { origin }\end{array}$ \\
\hline case 1 & 34 & 180 & 80.5 & Male & No & 77.2 & 40.1 & 83.5 & 65 & 56 & 71 & 89 & 67 & 7 Caucasian \\
\hline victim case 2 & 28 & 177 & 75 & Male & No & & & & & & 75 & 82.4 & & Caucasian \\
\hline
\end{tabular}

The next two examples illustrate the way ReEPh is working. A 28 years old man is the victim of an accidental radiation. Some parameters are missing in the second example whereas all the values are captured in the first example.

Table2. The first and second victim cases and the model case 1

The Table 2 shows the descriptor values of the victim case and the ones of the model case 1 with which it is compared. In that example, all the descriptor values have been captured by the user. In those examples, the similarity calculated for the victim case 1 is equal to 0.9585 and the confidence index 1 for the victim case 1 and is equal to 0.9756 whereas the confidence index is 0,5714 for the victim case 2 according to the formulas (2) and (3). 


\subsection{The visualization of the retrieved cases}

One problem that has been solved was the appropriateness of the representation and the way to graphically present and compare the possible solutions. The ReEPh GUI (Graphical User's Interface) allows users to compare all the model cases to the victim case graphically.

The Figure 2 shows the graphical representation of the victim case (the grey area) and the model case (the white area). Each axis represents one descriptor of the case. On each axis, the value of the victim case descriptor and the value of the same descriptor of the most similar model case are reported.

With this GUI, it is very easy to see how the cases are similar. It is also very simple to find out what the critic characteristics and differences are and to have an idea of the distance between two cases. As mentioned above, ReEPh retrieves a set of model cases.

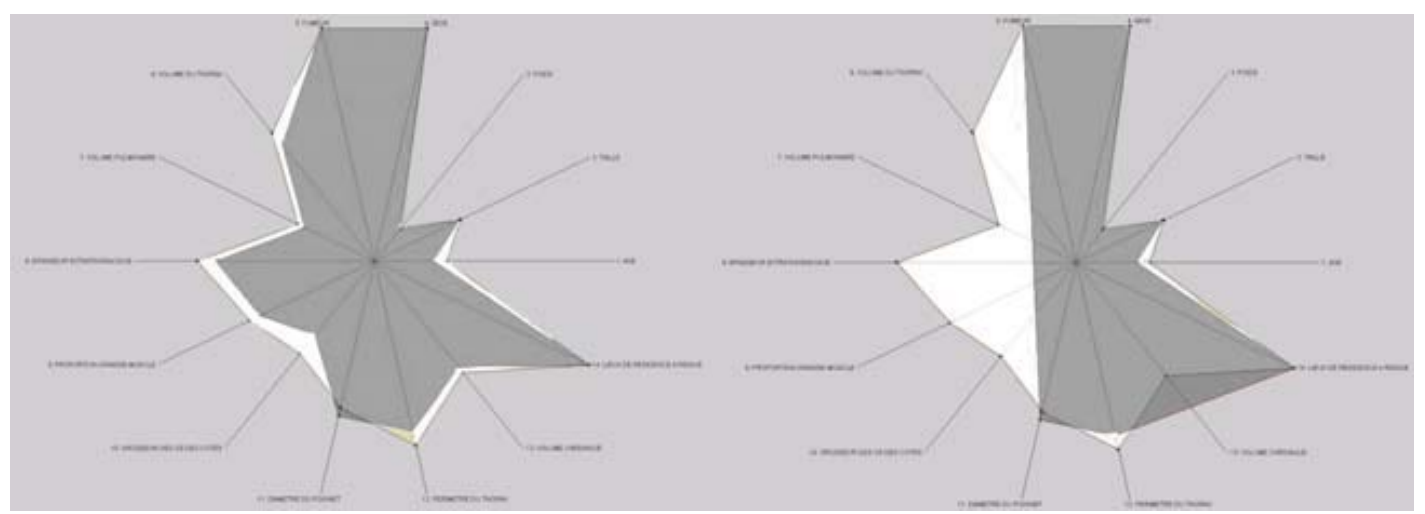

Figure 2. ReEPh graphical comparison of the victim case $(1 \& 2)$ with the model case 1 .

The Figure 2 is the GUI drawn by ReEPh obtained with the first and second victim case compared each other with the model case. As a matter of fact, the ReEPh GUI clearly shows that the cases are very similar if only the known values are taken into account, but it has to be put into perspective: the confidence index is average.

\section{Conclusion and prospects}

The development of a CBR-System presents a real challenge because it is a complex method that faces different sections. ReEPh proves it is possible to use the CBR principles for the field of the radiation protection. The first version of ReEPh has been implemented using basic algorithms, but taking into account all the constraints of this domain. Indeed, $\mathrm{ReEPh}$ allows the experts of radiation protection to find out the known phantom the most similar to one accidently irradiate victim considering the implanted descriptors. One case is characterized 
by a set of descriptors. Even if many of them are missing, ReEPh retrieves a set of phantoms.

Nevertheless, it is important to define wisely the descriptors and to choose the correct weights for the data treatment. The experts of radiation protection have to define more precisely the descriptors and their importance in order to improve the retrieval phase. The constraints of the domain have already been taken into account and integrated in this first version of ReEPh. There are three main tasks that should be treated in the future: the full extraction of all descriptors from a DICOM-file, an overwork of the approach that determines the most similar model case, maybe using ANN, and the adaptation of the proposed solution.

One of the main ideas about this adaptation algorithm is the fact that the most similar phantom may not always be the easiest to adapt. Consequently, in the future, we may not deal with the similarity, but with the adaptation easiness. This new aspect requires introducing more information of the domain: a real ontology of the phantoms used by experts of radiation protection will be necessary.

\section{Acknowledgments}

The authors want to acknowledge the SFRP (Société Française de Radioprotection) which has subsidized this preliminary work.

\section{References}

[1] I. Clairand, Développement de nouveaux modèles physiques dédiés à la dosimétrie interne par l'utilisation du code de Monte Carlo EGS. Thèse de l'Université Paul Sabatier, Toulouse, 1999.

[2] J. Coulot, Dosimétrie des émetteurs Bêta à l'échelle tissulaire et cellulaire par méthode de Monte-Carl, Thèse de l'Université Paris XI, 2004.

[3] W. S. Snyder, M. R. Ford, G.G. Warner, Estimates of absorbed fractions for mono-energetic photons sources uniformy distributed in various organs of a heterogeneous phantom, MIRD pamphlet number 5 revised, New York, The Society of Nuclear Medicine, 1978.

[4] M. Cristy, K. F. Eckerman, Specific absorbed fractions of energy at various ages from internal photons sources, ORNL Report/TM-8381, Oak Ridge, Oak Ridge National Laboratory, 1987.

[5] R. Kramer, M. Zankl, G. Williams, G. Dexter, The calculation of dose from external photon exposures using reference human phantoms and Monte Carlo methods. Part I: the male (Adam) and female (Eva) adult mathematical phantoms, Report GSF-Bericht S-885, München, GSF, 1982. 
[6] G. I. Tanaka, H. Kawamura, Y. Nakahara, Reference Japanese man-I. Mass of organs and other characteristics of normal Japanese, Health Physics, vol. 36, issue 3, 1979, pp. 333-346.

[7] M. Zank1, R. Viet, G. Williams, K. Schneider, H. Fendel, N. Petoussi, G. Dexler, The construction of computer tomographic phantoms and their application in radiology and radiation protection, Radiation Environmental Biophysics, vol. 27, 1988, pp. 153-164.

[8] M. Zankl, W. Panzer, N. Petoussi-Hens, G. Dexler, Organ doses for children from computed tomographic examinations, Radiation Protection Dosimetry, vol. 57, issue 1/4, 1995, pp. 393-396.

[9] P. J. Dimbylow, Induced current densities from low-frequency magnetic fields in a $2 \mathrm{~mm}$ resolution, anatomically realistic model of the body, Physics in Medicine and Biology, vol. 43, issue 2, 1998, pp. 221-230.

[10] I. G. Zubal, C. R. Harrell, E. O. Smith, Z. Rattner, G. Gindi, P. B. Hoffer, Computerized three dimensional segmented human anatomy, Medical Physics, vol. 21, issue 2, 1994, pp. 299-302.

[11] M. Caon, G. Bibbo, J. Pattison, An EGS-4ready tomographic computational model of 14-year-old female torso for calculating organ doses from CT examinations, Physics in Medicine and Biology, vol. 44, 1999, pp. 22132225.

[12]M. Zankl, A. Wittmann, The adult male voxel model 'Golem' segmented from whole-body CT patient data, Radiation Environment Biophysics, vol. 40, 2001, pp. 153-162.

[13] G. Lorin de la Grandmison, I. Clairand, M. Durigon, Organ weight in 684 adult autopsies : new tables for a Caucasoid population, Forensic Science International, vol. 119, 2001, pp. 149-154.

[14] S. W. Jacob, The complete visible man: the complete high resolution male and female anatomical datasets from the visible human project, Journal Am. Med. Assoc., vol. 281, issue 8, 1999, p. 765.

[15] X. G. Xu, T. C. Chao, A. Bozkurt, VIP MAN, an imaged-based wholebody adult male model constructed from color photographs of the visible human project for multi-particle Monte Carlo calculations, Health Physics, vol. 78, issue 5, 2000.

[16] C. E. Easterley, G. Allgood, K. F. Eckerman, B. Knee, M. Maston, G. MacNeilly, J. Munro, N. Munro, R. Toerite, B. Van Hoy, The virtual human: a diagnostic tool for human studies and health effects in the $21^{\text {st }}$ century, SPIE the international society for optical engineering, issue 3253, 1998, pp. 150-154.

[17] J. Kolodner, Case-Based Reasoning, Morgan Kaufmann Publishers, 1993. 